\title{
A high volume sampling system for isotope determination of volatile halocarbons and hydrocarbons
}

\author{
E. Bahlmann, I. Weinberg, R. Seifert, C. Tubbesing, and W. Michaelis \\ Institute for Biogeochemistry and Marine Chemistry, Hamburg, Germany \\ Received: 15 March 2011 - Published in Atmos. Meas. Tech. Discuss.: 8 April 2011 \\ Revised: 31 August 2011 - Accepted: 7 September 2011 - Published: 4 October 2011
}

\begin{abstract}
The isotopic composition of volatile organic compounds (VOCs) can provide valuable information on their sources and fate not deducible from mixing ratios alone. In particular the reported carbon stable isotope ratios of chloromethane and bromomethane from different sources cover a $\delta^{13} \mathrm{C}$-range of almost $100 \%$ making isotope ratios a very promising tool for studying the biogeochemistry of these compounds. So far, the determination of the isotopic composition of $\mathrm{C}_{1}$ and $\mathrm{C}_{2}$ halocarbons others than chloromethane is hampered by their low mixing ratios.

In order to determine the carbon isotopic composition of $\mathrm{C}_{1}$ and $\mathrm{C}_{2}$ halocarbons with mixing ratios as low as $1 \mathrm{pptv}$ (i) a field suitable cryogenic high volume sampling system and (ii) a chromatographic set up for processing these samples have been developed and validated. The sampling system was tested at two different sampling sites, an urban and a coastal location in Northern Germany. The average $\delta^{13} \mathrm{C}$-values for bromomethane at the urban site were $-42.9 \pm 1.1 \%$ ond agreed well with previously published results. But at the coastal site bromomethane was substantially enriched in ${ }^{13} \mathrm{C}$ by almost $10 \%$. Less pronounced differences were observed for chlorodifluoromethane, 1,1,1trichloroethane and chloromethane. We suggest that these differences are related to the turnover of these compounds in ocean surface waters. Furthermore we report first carbon isotope ratios for iodomethane $(-40.4 \%$ o to $-79.8 \%$ ), bromoform ( $-13.8 \%$ to $22.9 \%$ ), and other halocarbons.
\end{abstract}

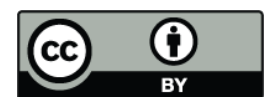

Correspondence to: E. Bahlmann (enno.bahlmann@zmaw.de)

\section{Introduction}

Compound specific isotope ratio mass spectrometry (CSIRMS) of non methane volatile organic compounds (NMVOCs) emerged as a powerful tool to distinguish different sources and to provide information on sinks (Rudolph et al., 1997; Rudolph and Czuba, 2000; Tsunogai et al., 1999; Bill et al., 2002; Thompson et al., 2002; Goldstein and Shaw, 2003 and references therein; Archbold et al., 2005; Redeker et al., 2007; Mead et al., 2008).

In particular, stable carbon isotope ratios have been proposed for constraining the origin and fate of atmospheric chloromethane (Harper et al., 2003; Keppler et al., 2005) and bromomethane (Mc Cauly et al., 1999); as the reported carbon isotope ratios of the known sources cover a broad range of $\delta^{13} \mathrm{C}$ values from $-40 \%$ or anthropogenic and marine sources to $-147 \%$ o for chloromethane synthesized from pectin (cf. Keppler et al., 2005). Tremendous progress has recently been made for the carbon isotopic analysis of dissolved halocarbons (Auer et al., 2006), which now allows to extend this approach to short lived halocarbons such as iodomethane $\left(\mathrm{CH}_{3} \mathrm{I}\right)$, dibromomethane $\left(\mathrm{CH}_{2} \mathrm{Br}_{2}\right)$ and bromoform $\left(\mathrm{CHBr}_{3}\right)$. Accompanying determination of the carbon isotope ratios of these compounds could provide valuable additional information that can not be derived from the determination of mixing ratios.

For determining carbon isotope ratio of atmospheric VOCs both, air sampling canisters (Rudolph et al., 1997; Tsunogai et al., 1999; Thompson et al., 2002; Archbold et al., 2005; Redeker et al., 2007) and adsorbent tubes (Mead et al., 2008) have successfully been used. Given a minimum carbon amount between $0.25 \mathrm{ng}$ and $1 \mathrm{ng}$ required for carbon isotope analysis, these sampling methods are sufficient

Published by Copernicus Publications on behalf of the European Geosciences Union. 
for measurements of chloromethane (Rudolph et al., 1997; Tsunogai et al., 1999; Thompson et al., 2002; Archbold et al., 2005, Redeker et al., 2007; Mead et al., 2008) and several chlorofluorocarbons and hydrofluorocarbons (Thompson et al., 2002; Redeker et al., 2007; Mead et al., 2008) but not for bromomethane and other halocarbons such as bromoform and iodomethane with typical mixing ratios between 0.5 and 10 pptv.

To the best of our knowledge, there is only one study reporting carbon isotope ratios for atmospheric bromomethane (Bill et al., 2004) in which a cryogenic sampling system was used.

The main objective of this study was to develop a simple and robust sampling system appropriate for field work enabling the isotope ratio determination of atmospheric halocarbons in the low pptv range, notably bromomethane, bromoform and iodomethane. Here, we describe the configuration and validation of the developed sampling system and report first results from its application within a survey on air samples from an urban (Hamburg, Germany) and a coastal site (Sylt, Germany).

\section{Methods}

\subsection{Overview}

Briefly, up to 5001 of air were drawn through a cryo trap. The trap was then heated to $125^{\circ} \mathrm{C}$ and the analytes were transferred to an adsorption tube for storage and analysis. A direct analysis of the isotopic composition of the target compounds is not possible due to multiple interferences from other compounds. Therefore, the samples were first pre-separated on a GasPro column and the target compounds were recollected on two cryo traps. For carbon isotope determination each fraction was then separated on a PorabondQ column and analysed on a GC-C-IRMS/MS system.

\subsection{Standards and samples}

A Scott EPA TO 15/17 standard containing 65 compounds (1 ppm each in nitrogen) was used as a working standard. For further tests single component standards of chloromethane, bromomethane, iodomethane and dichlorodifluoromethane (each $100 \mathrm{ppm}$ in nitrogen) were used.

Three ambient air samples were taken at the institute building in the center of Hamburg, Northern Germany $\left(53^{\circ} 56^{\prime} 86^{\prime \prime} \mathrm{N}, 9^{\circ} 97^{\prime} 36^{\prime \prime} \mathrm{W}\right)$ from 19 to 24 September 2010. The sampling system inlet was placed at $30 \mathrm{~m}$ above the ground. The sampling duration was $2 \mathrm{~h}$ and the start time varied between 10:00 am and 02:00 p.m. LT (= local time). Possible local sources include traffic exhaust, emissions from the harbor area and volatiles from laboratory activities in the vicinity.

In addition, three marine influenced air samples were taken at the AWI Wadden Sea Station in List/Sylt, Northern
Germany $\left(55^{\circ} 02^{\prime} 26^{\prime \prime}\right.$ N. $\left.8^{\circ} 43^{\prime} 96^{\prime \prime} \mathrm{W}\right)$ between 29 August and 5 September. The sampling system was placed directly at the coastline $200 \mathrm{~m}$ away from the Wadden Sea Station. As for the urban location the sampling duration was $2 \mathrm{~h}$ and the start time varied between 10:00 a.m. and 02:00 p.m. LT Potential local sources for halocarbons include emissions from salt marshes, tidal flats and, to a minor degree, harbor activities in List.

$72 \mathrm{~h}$ back trajectories were calculated by Hysplit 4.8 for an arriving height of $30 \mathrm{~m}$ (Hamburg samples) and $2 \mathrm{~m}$ (Sylt samples) using NCEP's Global Data Assimilation System (GDAS) data (Draxler and Rolph, 2011). The backward trajectories indicate a prevailing marine and coastal influence for the samples taken at Sylt and a prevailing continental influence for the samples taken at Hamburg.

\subsection{Sampling system}

The sampling system (Fig. 1) was designed with respect to field suitability and integrity of the isotopic composition of the target compounds. To avoid contamination, all system parts were made of stainless steel or silanized glass.

The sampling consists of three consecutive steps: (1) the cryogenic adsorption of the target compounds from ambient air, (2) the transfer of the analytes from the cryo trap to an adsorption tube and (3) the conditioning of the cryo trap.

1. During sampling the valves 1 and 2 were open. 300 to 5001 of ambient air were drawn with a membrane pump (KNF Neuberger N86 KNDC, Freiburg, Germany) through the sampling system with a flowrate between 3 and $51 \mathrm{~min}^{-1}$. The flowrate and the sampling volume were monitored with a mass flowmeter (Omega FMA-1608A, Deckenpfronn, Germany). The air first passed a particle filter (Sartorius, Teflon membrane filter, diameter: $45 \mathrm{~mm}$, pore size: $0.2 \mu \mathrm{m}$ ) and was then directed through a condenser kept at approximately $5{ }^{\circ} \mathrm{C}$ reducing the water vapour of the air. It has previously been shown that a condenser does not affect the recovery of high boiling compounds such as $\mathrm{CHBr}_{3}$ (Christoph et al., 2002). Finally, the target compounds were enriched in the cryotrap at a temperature of $\leq-110^{\circ} \mathrm{C}$ provided by a dry shipper.

2. After sampling, valve 1 and 2 were closed and valve 3 to the adsorption tube was opened. The cryotrap was carefully removed from the dry shipper. Co-trapped argon and traces of $\mathrm{O}_{2}$ and $\mathrm{N}_{2}$ were rapidly released into the gas phase. To prevent analyte losses during sample transfer (usually observed at a flowrate $>100 \mathrm{ml} \mathrm{min}^{-1}$ ), a restriction capillary (restriction flow $70 \mathrm{ml} \mathrm{min}^{-1}$ at 2 bar) was placed behind valve 3 . Without this restriction we observed losses of highly volatile analytes such as chloromethane and dichlorodifluoromethane. After $20 \mathrm{~min}$, valve 4 was opened for $40 \mathrm{~min}$, the cryo trap was heated to $125^{\circ} \mathrm{C}$ and flushed 


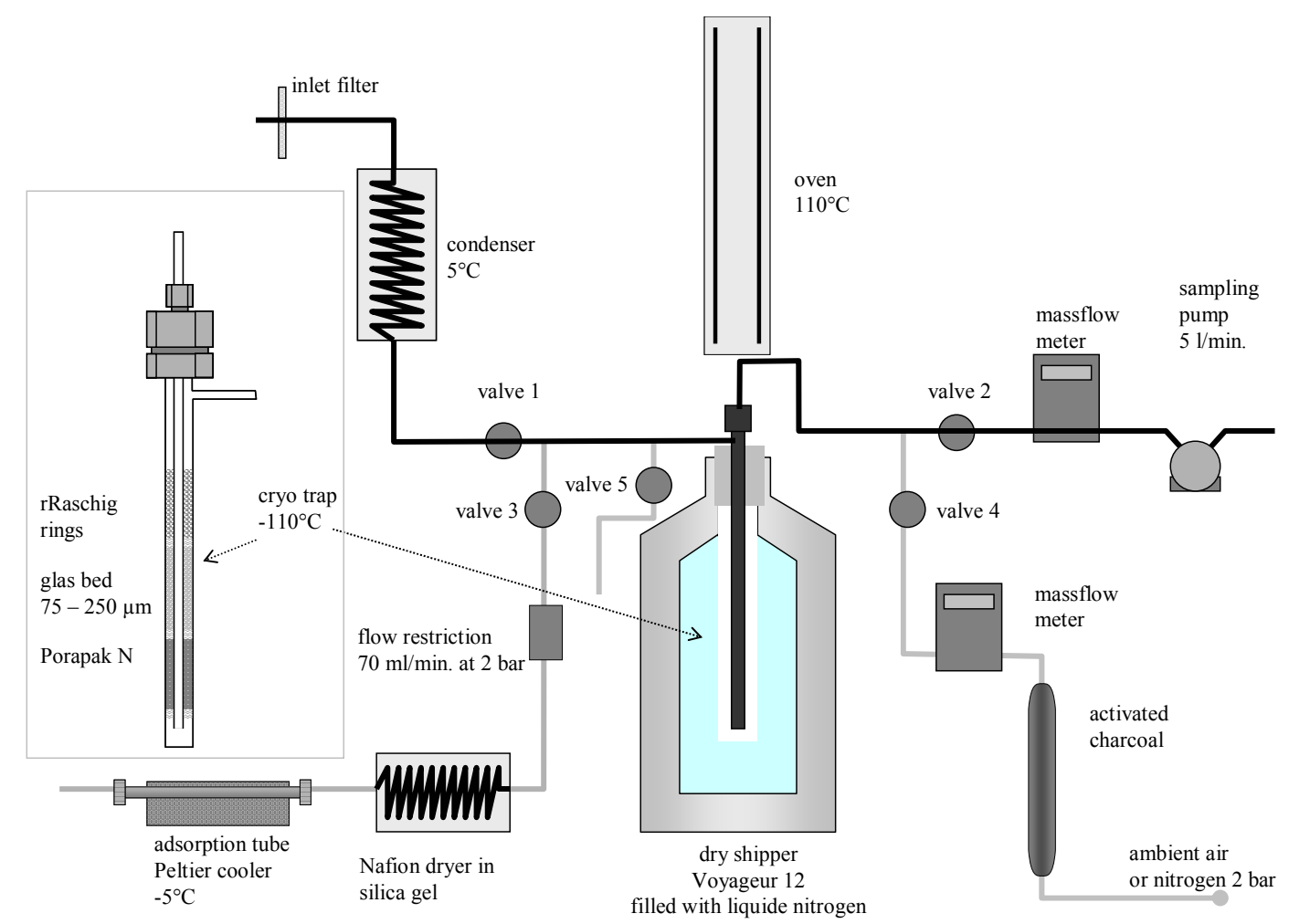

Fig. 1. Scheme of the sampling system.

with either nitrogen $\left(50 \mathrm{ml} \mathrm{min}{ }^{-1}\right)$ or pre cleaned ambient air. Before entering the adsorption tube, water vapour was removed from the gas stream by a Nafion dryer (Perma Pure Inc. NJ, USA) placed in silica gel. During sample transfer the adsorption tube was cooled to $-5^{\circ} \mathrm{C}$ using a Peltier cooler to prevent breakthrough of the analytes. Under these conditions non-polar compounds with a boiling point as high as $150^{\circ} \mathrm{C}$ were completely transferred from the cryo trap to the adsorption tube, while polar water soluble compounds, such as alcohols and aldehydes, were fractionated between the water remaining in the cryo trap and the adsorption tube. After the transfer of samples the adsorption tube was closed and stored at $\leq-80^{\circ} \mathrm{C}$ until analysis.

3. After sample transfer, valve 3 was closed and valve 5 was opened for conditioning the cryo trap with a stream of nitrogen $\left(1000 \mathrm{ml} \mathrm{min}^{-1}\right)$ for $30 \mathrm{~min}$ at a temperature of $125^{\circ} \mathrm{C}$.

\subsubsection{Cryofocussing and design of the cryotrap}

Classical cryogenic sampling systems use either liquid nitrogen or liquid argon for the extraction of the target compounds from air (Bill et al., 2004; Pupek et al., 2005; Zuiderweg et al., 2011). More recently, a cryostat has been applied in cryogenic sampling systems (Miller et al., 2008). However, both approaches require a well established technical infrastructure limiting the use of such sampling systems in field campaigns, especially for field work in remote areas. In order to overcome the limitations of classical cryogenic sampling systems we employed a dry shipper (Voyageur 12, Air Liquide, Düsseldorf, Germany) as a cooling source. A dry shipper is a dewar that contains an adsorbent taking up liquid nitrogen. The Voyageur 12 can adsorb up to 141 of liquid nitrogen and provides a temperature of $-176^{\circ} \mathrm{C}$ for 28 days in the gas phase above the adsorbed liquid nitrogen. It has an approval for air transport allowing cryogenic sampling in remote places where no liquid nitrogen is available. For the sampling system the stopcock of the dry shipper was shortened to $10 \mathrm{~cm}$ and a hole of $20 \mathrm{~mm}$ diameter was drilled into the stopcock to insert the cryo trap. The effective temperature inside the cryo trap depended on the flushing flow rate and was below $-110^{\circ} \mathrm{C}$ for flowrates up to $51 \mathrm{~min}^{-1}$.

The cryo trap consists of an outer stainless steel tube (3/4 inch, $50 \mathrm{~cm}$ length) with an air inlet at the side $4 \mathrm{~cm}$ below the top and an inner 1/4 inch stainless steel tube that is connected to the sampling pump (Fig. 1).

To achieve complete trapping at $-110^{\circ} \mathrm{C}$ the space between both tubes is filled with adsorbents separated by plugs of precleaned silanized glass wool. From the top to the bottom the package of the trap was as follows: $0-20 \mathrm{~cm}$ : empty; $20-25 \mathrm{~cm}$ silanized raschig rings; $25-35 \mathrm{~cm}$ silanized glass beads $60-250 \mu \mathrm{m} ; 35-41 \mathrm{~cm}$ Tenax TA; $41-47 \mathrm{~cm}$ Porapak N; 47-50 cm: empty. The empty space at the top and 
the silanized glass rings were mainly designated for trapping water vapour and $\mathrm{CO}_{2}$.

\subsubsection{Adsorption tubes}

The adsorption tubes were made of stainless steel $1 / 4$ inch outer diameter, 7 inch length) and filled with $77 \mathrm{mg}$ Carboxen $1016^{\circledR}, 215 \mathrm{mg}$ Carbopack X $569^{\circledR}, 80 \mathrm{mg}$ Carboxen ${ }^{\circledR}$ 1003 and 9 mg Tenax ${ }^{\circledR}$ TA in order of the sampling flow direction. The filling was fixed with stainless steel plugs. Silanized glass wool was used for separating the adsorbents. Before use, the packed tubes were conditioned for $24 \mathrm{~h}$ in a tube conditioner (TC 1/2, Gerstel, Mühlheim Germany) at $320^{\circ} \mathrm{C}$ and a flow of $100 \mathrm{ml} \mathrm{min}^{-1}$ of nitrogen.

\subsubsection{Removal of $\mathrm{CO}_{2}$ and water}

Before analysis water and $\mathrm{CO}_{2}$ must be removed. Chemical traps frequently used in trace gas analysis to remove excessive $\mathrm{CO}_{2}$, such as Ascarite or Soda lime (Rudolph et al., 1997; Redeker et al., 2007) reduce the recovery of polyhalogenated methyl halides especially of polybrominated compounds and thus have been ruled out. The adsorbents used in the adsorption tubes have a low affinity for $\mathrm{CO}_{2}$ and most of the $\mathrm{CO}_{2}$ from the cryo trap passes the adsorbent tubes during sample transfer. Prior to analysis, the adsorbent tubes were flushed with helium at room temperature $(2 \mathrm{~min}$, $20 \mathrm{ml} \mathrm{min}^{-1}$ ) further reducing the $\mathrm{CO}_{2}$ content of the samples. The remaining $\mathrm{CO}_{2}$ was removed during the $\mathrm{GC}$ preseparation by an initial flushing step.

Chemical traps such as magnesium perchlorate or phosphorus pentoxide are not suitable for water removal in highvolume sampling systems due to the large amount of water (up to $30 \mathrm{ml} \mathrm{m}^{-3}$ ) present in ambient air. Water was removed from the sample at three stages during sampling and analysis. First the water vapour pressure in the sampled air was reduced by means of a condenser kept at $5^{\circ} \mathrm{C}$. We found this suitable to prevent clogging of the cryo trap for air samples up to 5001 . The remaining air moisture was frozen out in the cryo trap. During the sample transfer only a small fraction of the water was mobilized from the cryo trap. This water was removed by a Nafion dryer placed in silica gel. Remaining traces of water were finally removed by means of a second Nafion dryer during analysis.

Nafion dryers have the potential for artefact formation. So far, transformation of carbonyl compounds to alcohols and reactions of compounds containing double or triple bonds have been reported (Miller et al., 2008).

During first tests, we attached the Nafion dryer in front of the cryo trap to reduce the water offload to the cryo trap. With this setup we observed elevated levels of bromomethane. Parallel runs with and without the Nafion dryer indicated an artificial formation of bromomethane on the Nafion membrane of up to 10 pptv. Further tests revealed that the sulfonic acid groups of the Nafion membrane can catalyze the nucleophilic substitution of methanol to bromomethane in the presence of bromide. Nevertheless, with the Nafion dryer behind the cryo trap we did not observe any artificial formation of bromomethane.

\subsection{Carbon isotope ratio determination}

A direct analysis of the isotopic composition of the target compounds was not possible due to multiple interferences from other compounds. Therefore, the sample was first pre-separated on a Gas-Pro column and the target compounds were recollected on two cryo traps. For carbon isotope determination each fraction was then separated on a PorabondQ column and analysed on a GC-C-IRMS/MS system. A scheme of the analytical set up is shown in Fig. 2. Two exemplary chromatograms showing the mass 44 trace and the $m / z 45 / 44$ ratio from a coastal sample as well as the mass spectra of selected halocarbons are presented in the Supplement.

\subsubsection{Pre-separation}

The pre-separation was performed on an 6890N/5975B GCMS (Agilent, Waldbronn, Germany). The analytes were desorbed from the adsorbent tube into a helium gas carrier at $330^{\circ} \mathrm{C}$ ( $\left.15 \mathrm{~min} ., 25 \mathrm{ml} \mathrm{min}^{-1}\right)$, directed through a Nafion dryer and refocused on a quartz capillary $(0.32$ i.d, $60 \mathrm{~cm}$ length) immersed in liquid nitrogen. Afterwards the analytes were desorbed at $25^{\circ} \mathrm{C}$ and separated on a GasPro column (Agilent, $30 \mathrm{~m}, 0.32 \mu \mathrm{m}$ i.d.) with helium as a carrier. The flowrate was set to $5 \mathrm{ml}$ for $4 \mathrm{~min}$ to remove the $\mathrm{CO}_{2}$ and then ramped to $2.7 \mathrm{ml} \mathrm{min}^{-1}$. The oven temperature program was as follows: $40^{\circ} \mathrm{C}$, hold for $5 \mathrm{~min}$; $6^{\circ} \mathrm{C} \mathrm{min}^{-1}$ to $240^{\circ} \mathrm{C}$, hold for $10 \mathrm{~min}$.

About $20 \%$ of the sample were directed into the MS via a split for monitoring the fractionation. The remaining $80 \%$ of the sample were directed to a Valco six port valve (Vici, Schenkon, Swiss) and recollected on two cryo traps (Silica steel 1/16\#, 0.32 i.d., $25 \mathrm{~cm}$ length), one containing the target compounds and the other containing the remaining components.

\subsubsection{Isotope ratio determination}

For the isotope ratio determination each fraction was analysed on a Thermo Finnigan GC-C-IRMS/MS system (Trace GC II; combustion Interface III; DeltaV IRMS and DSQ II) system using a CP-PorabondQ column (Varian, $25 \mathrm{~m}, 250 \mu \mathrm{m}$ i.d.) for final separation of the analytes. Again, $20 \%$ of the sample were directed to a Quadrupole mass spectrometer (Thermo Finnigan DSQ II) for monitoring the peak purity. The remaining $80 \%$ were directed to a commercial combustion interface (GC-combustion interface III; Thermo Finnigan) converting the analytes to $\mathrm{CO}_{2}$. Water was further removed by a Nafion dryer and about $0.5 \mathrm{ml} \mathrm{min}^{-1}$. of the 


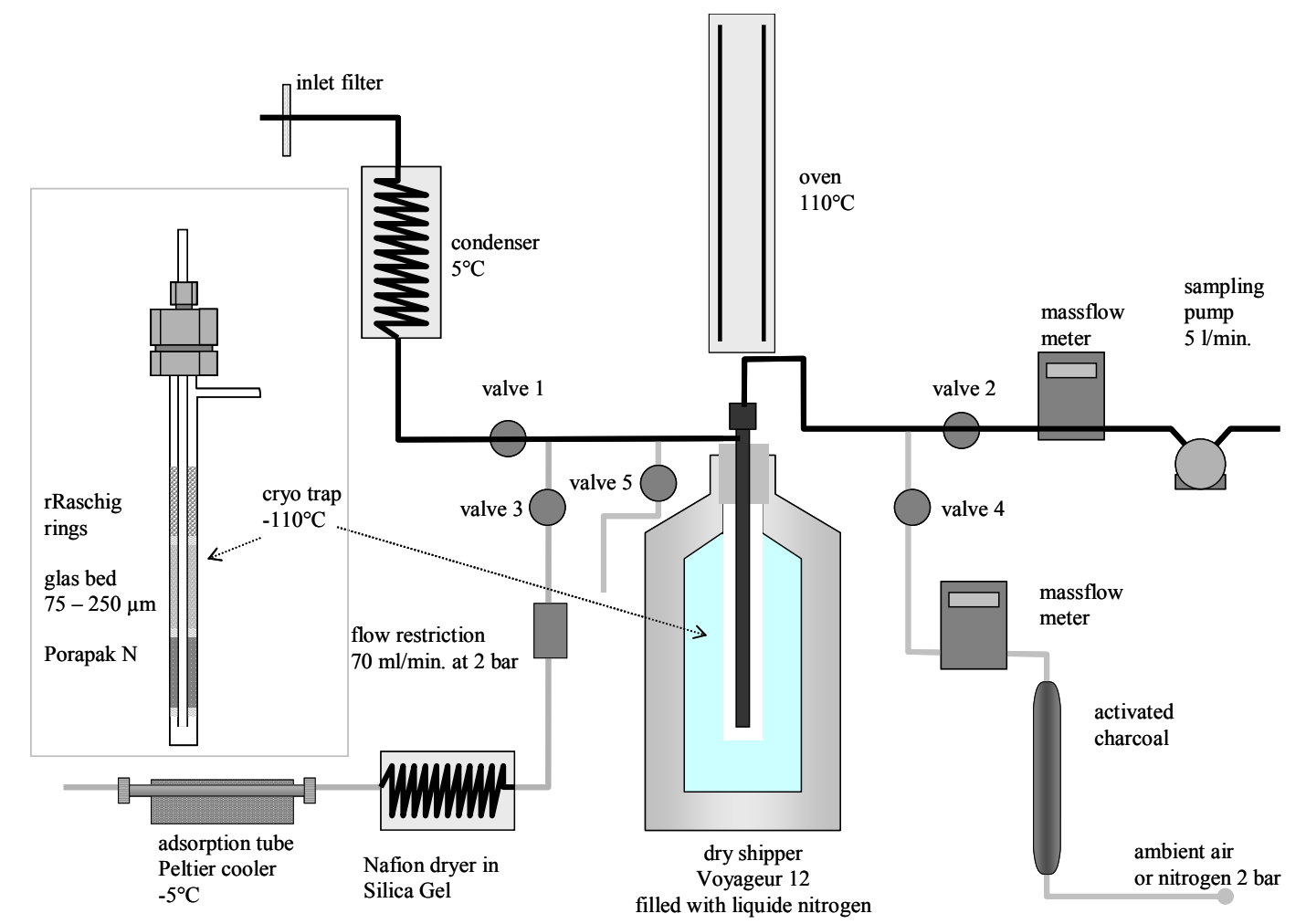

Fig. 2. Scheme of the analytical system.

flow were transferred to an DeltaV isotope ratio mass spectrometer via an open split.

Prior to sample analysis, the performance of the IRMS was evaluated by repeated injections of a certified $\mathrm{CO}_{2}$ reference gas (Air Liquide, Germany, $-26.8 \pm 0.2 \%$ ) via an open split. The Scott TOC EPA 15/17 standard was used as a daily working standard to monitor the repeatability. Results are only reported for peaks that met the following quality criteria: (i) peak purity better than $90 \%$ (ii) peak separation better than $90 \%$ valley.

All isotope values are reported relative to the Vienna Pee Dee Belemnite (VPDB) scale and within the lab uncertainties, unless otherwise stated, are reported on the $1 \sigma$ level.

\subsubsection{Identification, quantification and purity control of VOCs}

The analytes were identified by comparison of their retention time and mass spectra with known standards. Further compounds were identified by comparison of the obtained mass spectra with the Nist mass spectral database version 2.0. Primary quantification was done on the Agilent system used for pre-separation against the Scotty TOC EPA 15/17 standard. Compounds quantified against a standard were quantified on the IRMS via the $\mathrm{CO}_{2}$ intensities against chloromethane and bromomethane as internal standards. The uncertainty of this procedure is estimated to $\pm 15 \%$ on the $1 \sigma$ level. This es- timate is based on tests with known standards at different concentration levels. It is further justified from the variability of the mixing ratios determined for long lived compounds such as chlorodifluoromethane at the coastal sites as the variation of the mixing ratios for these compounds is typically less than a few percent in rural and background air masses.

\section{Results and discussion}

\subsection{Trapping and desorption efficiency of the sampling system}

The trapping and desorption efficiency was tested for the entire sampling procedure on a 0.2 nmole level by injecting $5 \mathrm{ml}$ of the Scott TOC EPA $15 / 17$ and $50 \mu$ of the iodomethane standard into a stream of nitrogen and preconcentrating the analytes on the cryo trap at a flow of $51 \mathrm{~min}^{-1}$ for $100 \mathrm{~min}$ (total volume 5001 ). Extraction was done as described above and the recovery rates were calculated against direct injections of the standard mixture onto the Agilent GC-MS system used for pre-separation and quantification.

The results of these tests are given in Table 1. The recovery rates for the entire sampling procedure averaged $97.8 \%$ (range from $87 \%$ to $110 \%$ ) and the reproducibility ranged from $1 \%$ to $7 \%$. Our data indicate a slight decrease of the 


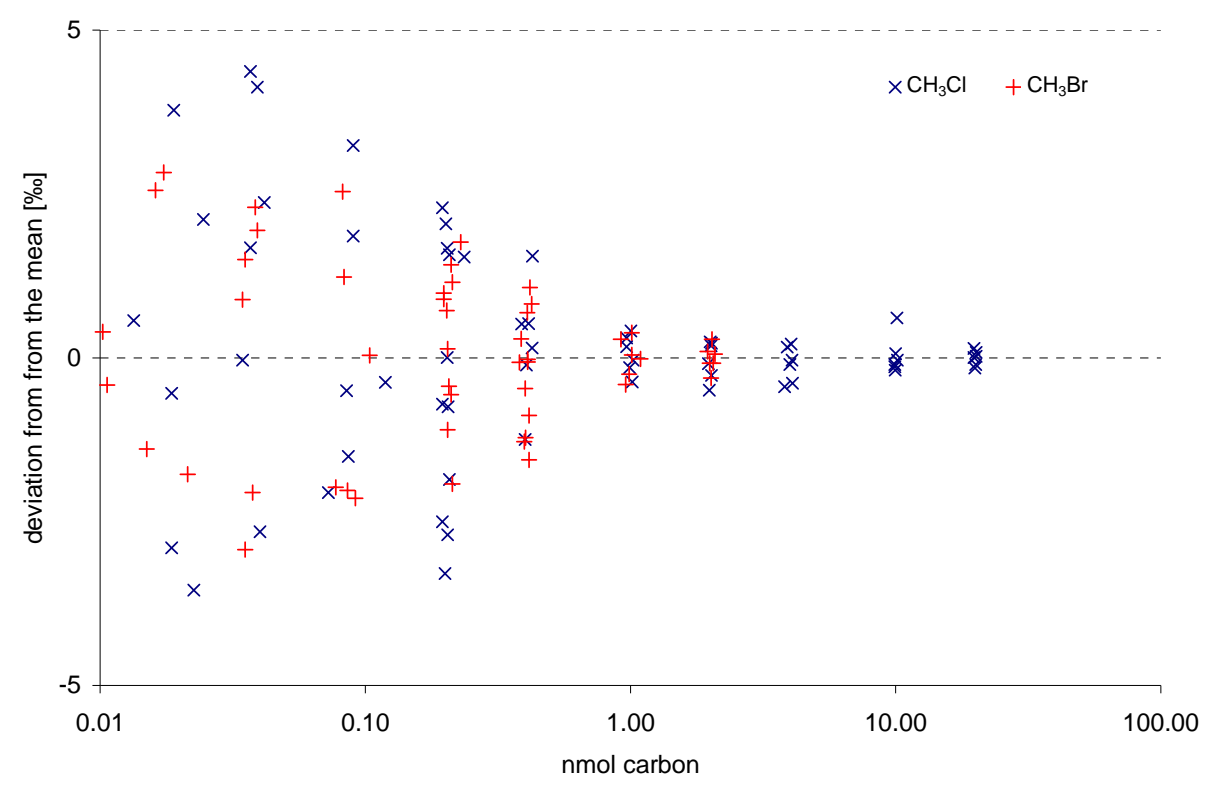

Fig. 3. Reproducibility of the $\delta^{13} \mathrm{C}$ measurements versus the carbon amount for $\mathrm{CH}_{3} \mathrm{Cl}$ and $\mathrm{CH}_{3} \mathrm{Br}$. Results are given as deviation from the mean. The respective means were calculated from all measurements with carbon amounts from 1.0 to $20 \mathrm{nmol}$. The mean $\delta^{13} \mathrm{C}$ values of the single component standards were $-32.5 \%$ and $-40.7 \%$ for $\mathrm{CH}_{3} \mathrm{Cl}$ and $\mathrm{CH}_{3} \mathrm{Br}$, respectively.

recovery rates with increasing boiling points for compounds with boiling points above $80^{\circ} \mathrm{C}$. However, there are no statistically significant differences between the recovery rates for direct injection on the adsorption tubes and those for the entire sampling process. Therefore, we conclude that no significant losses of the target analytes occur during sampling.

\subsection{Reproducibility of the carbon isotope determination}

\subsubsection{Reproducibility versus concentration}

Due to the low mixing ratios of some target compounds such as $\mathrm{CH}_{3} \mathrm{Br}, \mathrm{CH}_{3} \mathrm{I}$ and $\mathrm{CHBr}_{3}$ (usually $<10 \mathrm{pptv}$ ), we determined the linearity and reproducibility of the carbon isotope ratios for low levels of carbon in the sub-nmole range. This was performed by repeated injections of chloromethane and bromomethane into the GC-IRMS. The injected carbon amounts ranged from 0.02 to $20 \mathrm{nmol}$ ( $n \geq 6$ for each concentration level) corresponding to mixing ratios between 1 and 1000 pptv for a 5001 sample. The results of the reproducibility tests are depicted in Fig. 3. The carbon isotope ratio determination was free of a systematic bias for carbon amounts down to 0.02 nmole. The overall standard deviation for carbon amounts between 20 and 1 nmole were $0.25 \%$ for chloromethane $(n=30)$ and bromomethane $(n=12)$ respectively. The standard deviation for each concentration level $(n=6)$ varied between $0.12 \%$ and $0.30 \%$. However, below 1 nmole the standard deviation for both compounds increased and was $2.6 \%$ for chloromethane and $1.8 \%$ or bromomethane at carbon levels below 0.04 nmole. This corroborates the study of Rudolph et al. (1997) and Redeker et al. (2007) who observed similar deviations for comparable amounts of carbon.

\subsubsection{Reproducibility of the analytical system}

Since the sampling procedure showed an excellent recovery of $98 \pm 5 \%$, it is expected to be free of analytical artefacts. Blanks were checked on a routine base at regular intervals and the blanks contributed less than $0.5 \%$ to the overall signal. Thus, we can rule out blank contribution as a significant source of bias. Adsorptive losses or incomplete desorption of the target compounds remain as the most important source of bias during sampling. The kinetic isotope effects for such physical processes are generally small. For instance, adsorption of various aromatic hydrocarbons does not appear to cause significant carbon isotope fractionations (Goldstein and Shaw, 2003 and references therein). Even adsorptive losses of $10 \%$ that are associated with a hypothetical kinetic isotope effect of $5 \%$ would lead to a bias of less than $0.6 \%$. Thus, the reproducibility of the carbon isotope ratio determination was only tested for the analytical system. The effect of the pre-separation was tested on the 0.2 nmole level with the Scott TOC EPA 15/17 standard. $5 \mathrm{~mL}$ of the standard were injected into the GC-MS system, pre-separated and analysed for stable carbon isotope ratios as described in Sects. 3.41 and 3.42. Results were compared to the isotope ratios obtained without pre-separation. Without pre-seperation the isotopic composition could only be determined for 7 compounds because of coelutions and peak overlaps. After pre-separation, isotope ratios for 31 compounds 
Table 1. Comparison of the carbon isotope ratios obtained with and without pre-separation for the Scott Speciality Gases TOC $15 / 17$ standard and recovery rates for a sampling volume of 5001. Results are only given for compounds that were free of interferences from other compounds.

\begin{tabular}{|c|c|c|c|c|c|c|c|c|}
\hline & \multirow[b]{2}{*}{ compound } & \multirow[b]{2}{*}{$\mathrm{CAS}=$} & \multirow[b]{2}{*}{$\begin{array}{r}\mathrm{RT}= \\
\quad[\mathrm{s}]\end{array}$} & \multicolumn{3}{|c|}{ after pre-seperation } & \multicolumn{2}{|c|}{ direct injection } \\
\hline & & & & $\begin{array}{r}\text { Recovery } \\
\text { mean } \pm \sigma \\
{[\%]}\end{array}$ & $\begin{array}{c}\delta^{13} \mathrm{C} \\
\text { mean } \pm \sigma \\
{[\% o]}\end{array}$ & $n$ & $\begin{array}{l}\delta^{13} \mathrm{C} \\
\text { mean } \pm \sigma \\
{[\%]}\end{array}$ & $n$ \\
\hline 1 & Propene & $115-07-1$ & 743 & $93 \pm 5$ & $-27.9 \pm 0.5$ & 6 & & \\
\hline 2 & Chloromethane & $74-87-3$ & 744 & $109 \pm 3$ & $-61.3 \pm 1.9$ & 6 & & \\
\hline 3 & Methanol & $67-56-1$ & 790 & & $-39.6 \pm 1.8$ & 6 & & \\
\hline 4 & Dichlorodifluoromethane & $75-71-8$ & 908 & $101 \pm 2$ & $-31.0 \pm 1.9$ & 6 & & \\
\hline 5 & Vinylchloride & $75-01-04$ & 1026 & $107 \pm 2$ & $-30.1 \pm 1.0$ & 6 & & \\
\hline 6 & Bromomethane & $74-83-9$ & 1096 & $92 \pm 7$ & $-61.7 \pm 1.8$ & 6 & $-63.6 \pm 0.8$ & 6 \\
\hline 7 & Chloroethane & $75-00-3$ & 1196 & $102 \pm 3$ & $-30.9 \pm 0.9$ & 6 & & \\
\hline 8 & 1,2-dichloro-1,1,2,2-tetrafluoroethane & $76-14-2$ & 1243 & & $-27.0 \pm 0.8$ & 6 & & \\
\hline 30 & Iodomethane & $74-88-4$ & 1548 & $106 \pm 6$ & $-66.8 \pm 1.4$ & 6 & & \\
\hline 9 & Trichlorofluoromethane & $75-69-4$ & 1608 & $98 \pm 5$ & $-17.0 \pm 1.4$ & 6 & & \\
\hline 11 & 1,2 Dichloroethene trans & $156-60-5$ & 1763 & $100 \pm 4$ & $-21.2 \pm 0.9$ & 6 & $-21.2 \pm 1.0$ & 6 \\
\hline 12 & 1,2 Dichloroethene cis & $156-59-2$ & 1884 & $101 \pm 4$ & $-21.2 \pm 1.1$ & 6 & & \\
\hline 10 & 1,1 Dichloroethene & $75-35-4$ & 1628 & $98 \pm 4$ & $-29.1 \pm 6.6$ & 6 & & \\
\hline 13 & 1,1 Dichloroethane & $75-34-3$ & 1901 & $99 \pm 5$ & $-22.3 \pm 0.6$ & 6 & $-24.0 \pm 0.4$ & 6 \\
\hline 14 & $1,1,2$ trichloro- $1,2,2$ trifluoroethane & $76-13-1$ & 1963 & $100 \pm 3$ & $-24.1 \pm 1.3$ & 6 & & \\
\hline 19 & Chloroform & $67-66-3$ & 1986 & $100 \pm 5$ & $-44.3 \pm 1,6$ & 6 & $-45.1 \pm 1.1$ & 6 \\
\hline 15 & 1,2 Dichloroethane & $107-06-2$ & 2094 & $97 \pm 4$ & $-26.7 \pm 0.7$ & 6 & & \\
\hline 20 & Benzene & $71-73-2$ & 2216 & $97 \pm 2$ & $-26.8 \pm 0.5$ & 6 & & \\
\hline 23 & Carbontetrachloride & $56-23-5$ & 2225 & $96 \pm 1$ & $-41.1 \pm 1.1$ & 6 & & \\
\hline \multirow[t]{2}{*}{29} & Hexane & $110-54-3$ & 2249 & & $-29.9 \pm 0.9$ & 6 & & \\
\hline & Trichloroethene & $79-01-06$ & 2252 & $96 \pm 2$ & $-39.6 \pm 0.8$ & 6 & & \\
\hline 27 & Bromodichloromethane & $75-27-4$ & 2295 & $98 \pm 2$ & $-50.1 \pm 0.8$ & 6 & $-48.6 \pm 0.5$ & 6 \\
\hline 21 & Cyclohexane & $110-82-7$ & 2297 & $93 \pm 3$ & $-27.3 \pm 0.6$ & 6 & & \\
\hline 17 & 1,1,2 Trichloroethene & $79-00-5$ & 2536 & $95 \pm 2$ & $-29.2 \pm 1,1$ & 6 & & \\
\hline 22 & Dibromochloromethane & $124-48-1$ & 2584 & $90 \pm 2$ & $-44.3 \pm 1.4$ & 6 & & \\
\hline 18 & 1,2 Dibromoethane & $106-93-4$ & 2613 & $92 \pm 2$ & $-21.2 \pm 2.5$ & 6 & & \\
\hline 24 & Heptane & $142-82-5$ & 2623 & $98 \pm 2$ & $-26.5 \pm 1.4$ & 6 & & \\
\hline 25 & Chlorobenzene & $108-90-7$ & 2777 & $93 \pm 2$ & $-26.4 \pm 1.1$ & 6 & & \\
\hline 26 & Bromoform & $75-25-2$ & 2856 & $87 \pm 4$ & $-33.8 \pm 2.8$ & 6 & $-38.6 \pm 3.1$ & 6 \\
\hline 28 & Ethylbenzene & $100-41-4$ & 3001 & $85 \pm 3$ & $-27.7 \pm 0.8$ & 6 & & \\
\hline
\end{tabular}

could be determined. The results for these compounds are displayed in Table 1.

Standard deviations $(n=6)$ ranged from $0.5 \%$ for propene and benzene to $2.8 \%$ for bromoform and generally decreased with increasing numbers of carbon atoms. The average standard deviation for $\mathrm{C}_{1}$-compounds, $\mathrm{C}_{2}$-compounds and $\mathrm{C}_{3}$-compounds were $1.5 \%, 1.1 \%$ and $0.9 \%$, respectively. A Mann-Whitney-U-test $(p<0.05)$ revealed usually no significant influence of the pre-separation on the carbon isotope ratios. However, a significant difference between both procedures has been observed for bromoform (direct: $-38.6 \pm 3.1 \%$; $n=6$; pre-separation: $-33.8 \pm 2.8, n=6 ; p=0.025)$ and for 1,1-dichloroethane (direct: $-24.0 \pm 0.4 \%$; pre-separation: $-22.3 \pm 0.6, n=6$; $p=0.004)$.

\subsection{Ambient air samples}

The carbon isotope ratios and mixing ratios of the ambient air samples as well as results from previous studies are presented in Table 2. The range of the carbon isotope ratios of selected halocarbons is depicted in Fig. 4. Data are only presented for compounds which could be clearly identified either by comparison with standards or by their mass spectra and which met the quality criteria outlined above. In total, we could determine carbon isotope ratios of 37 compounds with mixing ratios between $0.3 \mathrm{pptv}$ for chlorobenzene and up to $1600 \mathrm{pptv}$ for propane. The high amounts of hydrocarbons in urban air samples caused strongly tailing peaks in the IRMS and thus prevented the carbon isotope determination of several organohalogens. This applied for chloroethane, 
iodomethane, chloroform, and bromoform in all and for carbon tetrachloride and 1,1,2-trichloro-1,2,2-triflouorethane in some of the urban air samples.

\subsubsection{Hydrocarbons and oxygenated VOCs}

The carbon isotope ratios obtained for the hydrocarbons agree with the results of previous studies (Rudolph et al., 1997; Tsunogai et al., 1999; Redeker et al., 2007). $\delta^{13} \mathrm{C}$ values of the alkanes propane, butane, isobutane, pentane and isopentane ranged from $-31.8 \%$ to $-25.0 \%$ with individual standard deviations between $0.8 \%$ o to $2.2 \%$. Except for butane that co-eluted with 1,2-dichloro-1,1,2,2tetrafluoroethane, the compounds were well separated. The portion of 1.2-dichloro-1.1.2.2-tetrafluoroethane to the butane carbon was less than $2 \%$ in urban samples and therewith negligible. In samples from the coastal site this portion amounted to 5 to $20 \%$ and thus may have affected the carbon isotope ratio determination of butane. However, the carbon isotope ratios from both sites showed no significant differences. Even though the average mixing ratios between both sites differed by roughly one order of magnitude (urban site: 304-1620 pptv; coastal site: 11-193 pptv), we observed no significant differences in $\delta^{13} \mathrm{C}$-values neither between the alkanes nor between the two sites. This is in line with the small fractionation factors (1.41-3.44\%o) reported for the reaction of alkanes with OH- radicals (Rudolph et al., 2000). Furthermore, the alkanes most likely stem from local traffic related sources at both sites and therefore obtain similar isotopic signatures.

On average the alkenes, propene and 2-butene were enriched in ${ }^{13} \mathrm{C}$ by $3.0 \%$ relative to the alkanes, which is conform to previous studies (Redeker et al., 2007). Propadiene and 2-butyne were even more enriched with $\delta^{13} \mathrm{C}$-values of $-18.1 \pm 0.3 \%$ and $-13.6 \pm 8.2 \%$ o, respectively. Propene, the only unsaturated hydrocarbon that could be determined at both sites, showed no site specific differences in the $\delta^{13} \mathrm{C}$ values. As the atmospheric degradation of propene by $\mathrm{OH}-$ radicals is assigned with a considerable fractionation factor of $11.7 \%$ (Rudolph et al., 2000), the lack of a site specific difference in $\delta^{13} \mathrm{C}$ thus points towards local sources rather than towards propene transported over a long distance from urban to coastal areas.

We also could determine carbon isotope ratios of several oxygenated compounds including dimethylether (DME), furane, propanal and propenal, which were identified based on their mass-spectra. The carbon isotope ratios of the aldehydes $(-25.4 \pm 1.6 \%$ ) were mainly in the same range as those of the alkenes with the exception of propenal that was strongly enriched in the urban air samples $(-17.2 \pm 2.3 \%$ ). Furane showed $\delta^{13} \mathrm{C}$ values of $-29.0 \pm 1.3 \%$. DME was depleted relative to the saturated hydrocarbons showing a mean $\delta^{13} \mathrm{C}$-value of $-34.1 \pm 0.8 \%$ in the urban samples and of $-37.2 \%$ at the coastal site.

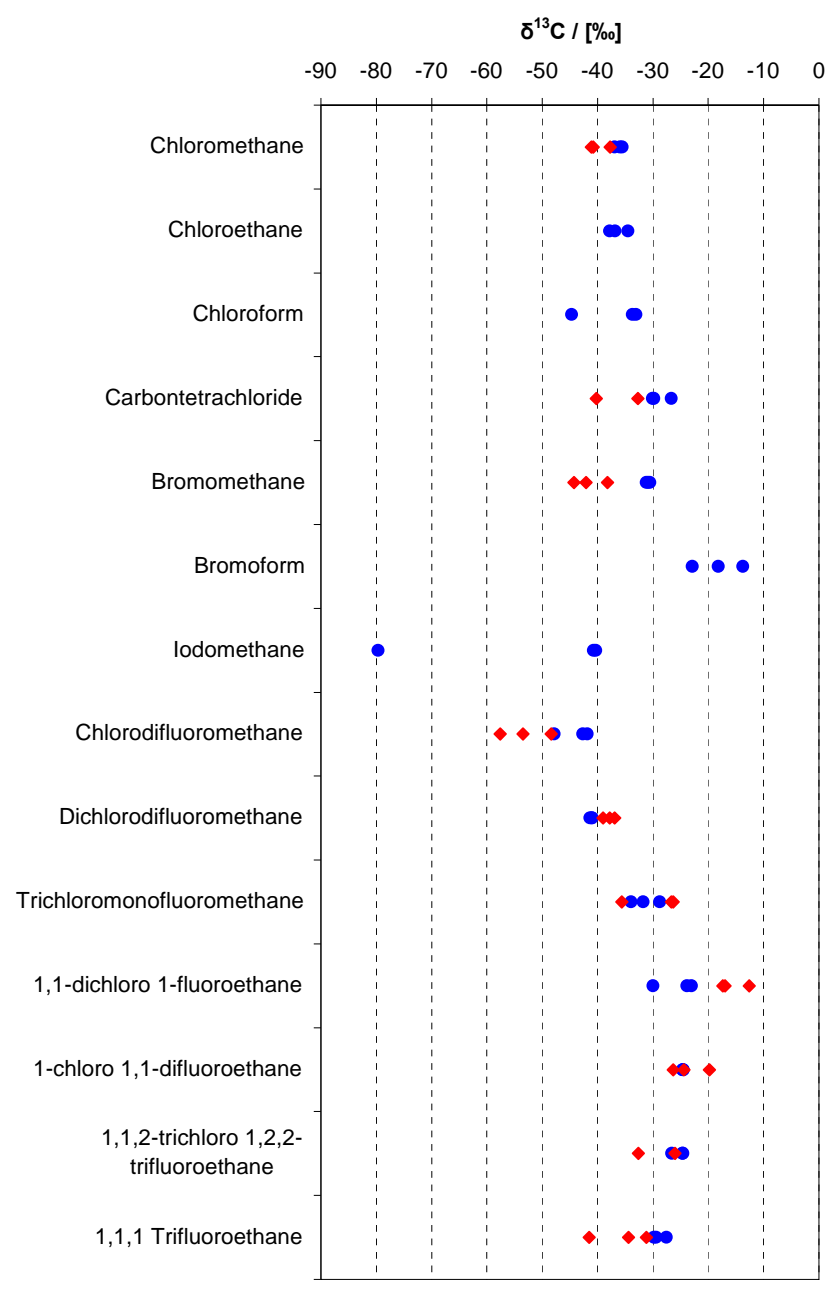

Fig. 4. Variability of the $\delta^{13} \mathrm{C}$ values of selected halocarbons in urban and coastal air samples. Urban air samples are marked with red diamonds and coastal samples are marked with blue dots.

\subsubsection{Organohalogens}

The mixing ratios of the long-lived CFCs and chloromethane generally fell within $\pm 30 \%$ of the atmospheric background levels. The average carbon isotope ratios of the organohalogens covered a broad range of $\delta^{13} \mathrm{C}$-values. Vinylchloride was strongly enriched in ${ }^{13} \mathrm{C}$ with an average $\delta^{13} \mathrm{C}$ value of $0.5 \%$. In contrast, hexafluoropropene was strongly depleted in ${ }^{13} \mathrm{C}$ with average $\delta^{13} \mathrm{C}$ value of $-57.1 \%$.

\section{- Dichlorodifluoromethane (CFC-12):}

The average mixing ratios of dichlorodifluoromethane $(614 \pm 60 \mathrm{pptv}$ for the urban site and $554 \pm 87 \mathrm{pptv}$ for the coastal site) showed no significant difference between the two sites. The average $\delta^{13} \mathrm{C}$ value was $-39.6 \%$ with slightly enriched $\delta^{13} \mathrm{C}$ values at the urban site (coastal site: $-41.2 \pm 0.2 \%$; urban site: $-37.9 \pm 1.1 \%$ ). Our data are in the range reported by Redeker et al. (2007), who gave an average $\delta^{13} \mathrm{C}$ 
Table 2. Averaged concentrations and isotopic values for all compounds reported in this paper from the coastal and the urban sampling site.

\begin{tabular}{|c|c|c|c|c|c|c|c|c|c|}
\hline \multirow[b]{2}{*}{ Compound } & \multirow[b]{2}{*}{$\mathrm{CAS}=$} & \multirow[b]{2}{*}{$\begin{array}{r}\mathrm{RT}= \\
\quad[\mathrm{s}]\end{array}$} & \multicolumn{3}{|c|}{ Coastal site } & \multicolumn{3}{|c|}{ Urban site } & \multirow{2}{*}{$\begin{array}{l}\text { other studies } \\
\text { mean } \pm \sigma\end{array}$} \\
\hline & & & $\begin{array}{l}\text { mixing ratio } \\
\text { mean } \pm \sigma \\
{[p p t v]}\end{array}$ & $\begin{array}{l}\delta^{13} \mathrm{C} \\
\text { mean } \pm \sigma \\
{[\% \text { o }]}\end{array}$ & $n$ & $\begin{array}{l}\text { mixing ratio } \\
\text { mean } \pm \sigma \\
{[p p t v]}\end{array}$ & $\begin{array}{l}\delta^{13} \mathrm{C} \\
\text { mean } \pm \sigma \\
{[\% o]}\end{array}$ & $n$ & \\
\hline 1.1.1 Trifluoroethane* & $420-46-2$ & 546 & $12 \pm 0.3$ & $-29.0 \pm 1.3$ & 2 & $13.1 \pm 0.4$ & $-35.7 \pm 5.3$ & 3 & - \\
\hline Bromotrifluoromethane* & $75-63-8$ & 610 & $3.7 \pm 0.2$ & $-39.1 \pm 10.3$ & 2 & & & & - \\
\hline Hexafluoropropene* & $116-15-4$ & 687 & $1.2 \pm 0.1$ & $-57.1 \pm 1.9$ & 2 & & & & - \\
\hline Chlorodifluoromethane & $75-45-6$ & 703 & $231 \pm 26$ & $-44.2 \pm 3.3$ & 3 & $222.0 \pm 25$ & $-53.2 \pm 4.6$ & 3 & $\begin{array}{l}-42.9 \pm 5.6^{\mathrm{b}} \\
-33.9 \pm 1.0^{\mathrm{c}}\end{array}$ \\
\hline Propene & $115-07-1$ & 743 & $61 \pm 33$ & $-26.3 \pm 1.0$ & 3 & $73 \pm 21$ & $-24.3 \pm 2.1$ & 3 & $\begin{array}{l}-25.0 \pm 2.5^{\mathrm{b}} \\
-21.6 \pm 4.0^{\mathrm{e}}\end{array}$ \\
\hline Chloromethane & $74-87-3$ & 744 & $620 \pm 30$ & $-36.2 \pm 0.7$ & 3 & $524 \pm 36$ & $-39.9 \pm 1.9$ & 3 & $\begin{array}{l}-36.2 \pm 0.3^{\mathrm{a}} \\
-39.0 \pm 2.3^{\mathrm{b}} \\
-29 \text { to }-45^{\mathrm{c}} \\
-37.4^{\mathrm{h}}\end{array}$ \\
\hline Propane* & $74-98-6$ & 819 & $193 \pm 75$ & $-28.1 \pm 0.8$ & 3 & $1615 \pm 413$ & $-29.4 \pm 1.3$ & 3 & $\begin{array}{l}-29.8 \pm 1.3^{\mathrm{b}} \\
-27.1 \pm 1.5^{\mathrm{e}}\end{array}$ \\
\hline Propadiene* & $463-49-0$ & 831 & & & & $10.6 \pm 4.1$ & $-18.1 \pm 0.3$ & 2 & - \\
\hline Cyclopropane* & $75-19-4$ & 834 & $16 \pm 3$ & $-24.9 \pm 0.2$ & 2 & & & & - \\
\hline Dimethylether* & $115-10-6$ & 893 & $10.0 \pm 8$ & $-36.5 \pm 1.9$ & 3 & $87 \pm 36$ & $-34.1 \pm 0.8$ & 3 & - \\
\hline Dichlorodifluoromethane & $75-78-1$ & 908 & $554 \pm 88$ & $-41.2 \pm 0.2$ & 3 & $614 \pm 60$ & $-37.9 \pm 1.1$ & 3 & $\begin{array}{l}-37.2 \pm 3.9^{b} \\
-33.5 \pm 0.8^{c}\end{array}$ \\
\hline Vinylchloride & $75-01-4$ & 1026 & & & & $5.3 \pm 3.5$ & $-0.5 \pm 2.1$ & 2 & - \\
\hline Bromomethane & $74-83-9$ & 1096 & $7.0 \pm 1$ & $-31.0 \pm 0.3$ & 3 & $10.0 \pm 3.0$ & $-41.5 \pm 3.3$ & 3 & $-43.0 \pm 1.7^{\mathrm{f}}$ \\
\hline 1-Chloro-1.1-difluoroethane* & $75-68-3$ & 1112 & $25 \pm 2$ & $-24.6 \pm 0.1$ & 3 & $27.3 \pm 1.3$ & $-23.5 \pm 3.2$ & 3 & - \\
\hline Isobutane* & $75-28-5$ & 1171 & $15 \pm 8$ & $-29.4 \pm 1.8$ & 3 & $503 \pm 167$ & $-28.2 \pm 1.1$ & 3 & $-29.0 \pm 1.2^{\mathrm{b}}$ \\
\hline Chloroethane & $75-00-3$ & 1196 & $2.0 \pm 0.7$ & $-36.5 \pm 1.7$ & 3 & & & & - \\
\hline Butane* & $106-97-8$ & 1243 & $52 \pm 23$ & $-28.3 \pm 0.9$ & 3 & $304 \pm 109$ & $-28.0 \pm 1.8$ & 3 & $\begin{array}{l}-28.5 \pm 1.1^{\mathrm{b}} \\
-28.5 \pm 1.7^{\mathrm{e}}\end{array}$ \\
\hline Propenal* & $107-02-8$ & 1319 & $96 \pm 140$ & $-24.6 \pm 1.5$ & 3 & $6.1 \pm 2.7$ & $-17.2 \pm 2.3$ & 3 & - \\
\hline Propene-methyl* & $115-11-7$ & 1336 & $186 \pm 99$ & $-25.5 \pm 2.1$ & 3 & & & & $21.4 \pm 3.7^{\mathrm{b}}$ \\
\hline Furane* & $110-009$ & 1350 & $2.1 \pm 0.4$ & $-29.3 \pm 1.8$ & 3 & & & & - \\
\hline Propanal* & $123-38-6$ & 1358 & $242 \pm 86$ & $-24.3 \pm 1.8$ & 3 & & & & $-26.2 \pm 2.4^{\mathrm{g}}$ \\
\hline Iodomethane & $74-88-4$ & 1377 & $2.6 \pm 2.1$ & $-53.6 \pm 22.6$ & 3 & & & & - \\
\hline 2-Butene cis & $519-18-1$ & 1570 & $138 \pm 31$ & $-25.5 \pm 2.1$ & 3 & & & & $\begin{array}{l}-25.9 \pm 4.9^{\mathrm{b}} \\
-24.5 \pm 6.5^{\mathrm{e}}\end{array}$ \\
\hline Trichlorfluoromethane & $75-69-4$ & 1608 & $277 \pm 14$ & $-31.5 \pm 2.6$ & 3 & $283.0 \pm 26$ & $-29.5 \pm 5.3$ & 3 & $-27.3 \pm 4.4^{b}$ \\
\hline 1.1-Dichloro-1-flouorethane* & $1717-00-6$ & 1646 & $22 \pm 5$ & $-25.7 \pm 3.8$ & 3 & $8.0 \pm 0.9$ & $-15.7 \pm 2.9$ & 3 & - \\
\hline Isopentane* & $78-78-4$ & 1694 & $32 \pm 22$ & $-29.5 \pm 1.6$ & & $680 \pm 210$ & $-31.7 \pm 1.2$ & 3 & $-28.0 \pm 1.9^{b}$ \\
\hline 2-Butyne* & $503-17-3$ & 1736 & & & & $0.4 \pm 0.2$ & $-13.6 \pm 8.2$ & 2 & $-21.7 \pm 4.2^{\mathrm{b}}$ \\
\hline Pentane* & $109-66-0$ & 1737 & $20 \pm 10$ & $-31.0 \pm 1.2$ & 3 & $530 \pm 100$ & $-28.3 \pm 1.4$ & 3 & $\begin{array}{l}-27.4 \pm 2.2^{\mathrm{b}} \\
-27.7 \pm 1.3^{\mathrm{e}}\end{array}$ \\
\hline 1.1.2-Trichloro-1.2.2-Triflouroethane & $76-13-1$ & 1963 & $69 \pm 37$ & $-25.4 \pm 1.1$ & 3 & $72 \pm 21$ & $-29.3 \pm 4.7$ & 2 & $\begin{array}{l}-23.3 \pm 9.6^{\mathrm{a}} \\
-28.1 \pm 4.6^{\mathrm{b}}\end{array}$ \\
\hline Chloroform & $67-66-3$ & 1968 & $10.0 \pm 2.1$ & $-37.2 \pm 6.5$ & 3 & $22 \pm 11$ & & & $\begin{array}{l}-37.4 \pm 6.4^{\mathrm{b}} \\
-22.5 \pm 1.7^{\mathrm{c}}\end{array}$ \\
\hline Carbontetrachloride & $56-23-5$ & 2225 & $104 \pm 0$ & $-28.9 \pm 1.9$ & 3 & $92 \pm 25$ & $-36.5 \pm 5.3$ & 2 & $-27.1 \pm 1.2^{\mathrm{c}}$ \\
\hline 1.2-Dichloropropane & $78-87-5$ & 2396 & 1.1 & -29.5 & 1 & & & & - \\
\hline Trichloroethene & $79-01-06$ & 2536 & & & & 44 & -34.4 & 1 & $-18.1 \pm 9.1^{\mathrm{c}}$ \\
\hline Toluene & $108-88-3$ & 2660 & $34 \pm 16$ & $-26.8 \pm 0.6$ & 3 & & & & $-25.0 \pm 1.1$ \\
\hline Chlorobenzene & $108-90-7$ & 2777 & $0.3 \pm 0.1$ & $-26.9 \pm 6.8$ & 2 & & & & - \\
\hline Bromoform & $75-25-2$ & 2856 & $2.4 \pm 0.5$ & $-18.3 \pm 4.6$ & 3 & & & & - \\
\hline
\end{tabular}

* Mixing ratios have been calculated from the $\mathrm{CO}_{2}$ intensities on the IRMS against chloromethane and bromomethane as internal standards.

${ }^{\mathrm{a}}$ Thompson et al. (2002), ${ }^{\mathrm{b}}$ Redeker et al. (2007), ${ }^{\mathrm{c}}$ Mead et al. (2008), ${ }^{\mathrm{d}}$ Tsunogai et al. (1999), ${ }^{\mathrm{e}}$ Rudolph et al. (2002), ${ }^{\mathrm{f}}$ Bill et al. (2004), ${ }^{\mathrm{g}}$ Giebel et al. (2010), ${ }^{\mathrm{h}}$ Rudolph et al. (1997) 
value of $-37.1 \pm 3.9 \%$ from a coastal and an urban area in Ireland, but are depleted in comparison to those reported by Mead et al. (2008) from Bristol, UK $(-33.5 \pm 0.8 \% o)$.

\section{- Chloromethane:}

Chloromethane mixing ratios were $524 \pm 36 \mathrm{pptv}$ for the urban and $620 \pm 30 \mathrm{pptv}$ for the coastal site. The $\delta^{13} \mathrm{C}$ value average over both sites was $-38.0 \pm 4.1 \%$ o $(n=7)$ with a slight difference between the urban $(-39.9 \pm 1.9 \%)$ and the coastal site $(-36.2 \pm 0.7 \%$ ) . The values mirror previously published results. Tsunogai (1999) and co-workers reported an average $\delta^{13} \mathrm{C}$ of $-36 \%$ or the marine background in the subtropical Pacific. Thompson et al. (2002) determined an average $\delta^{13} \mathrm{C}$ value of $-36.4 \pm 1.6 \%$ from a remote site in the arctic (Alert, Canada). Slightly more depleted values of $-39 \pm 2.3 \%$ were reported by Redeker et al. (2007) from Belfast, Ireland.

\section{- Bromomethane:}

The $\delta^{13} \mathrm{C}$-values of bromomethane in the urban samples were $-41.5 \pm 3.3 \%$ o $(n=4)$ being in excellent agreement with the only previous reported values of $-43.0 \pm 1.7 \%$ from a suburban site in Berkely, USA (Bill et al., 2004). At the coastal site the $\delta^{13} \mathrm{C}$-values averaged $-31.0 \pm 0.3 \%$. This isotopic enrichment by $10 \%$ is accompanied by a decrease of the average mixing ratios from $10 \pm 3 \mathrm{pptv}$ at the urban site to $7 \pm 1 \mathrm{pptv}$ at the coastal site. However this difference in the mixing ratios is mainly driven by one urban sample showing an elevated mixing ratio and thus we cannot state a systematic relation between the carbon isotope ratios and the mixing ratios.

\section{- Iodomethane:}

Iodomethane coeluted with carbon disulfide, dichloromethane and propenal. Although the mixing ratios in all samples were generally sufficient for the carbon isotope ratio determination we were only able to determine carbon isotope ratios of iodomethane in the coastal samples after a careful adjustment of the time intervals for the fractionation of the samples.

Iodomethane belongs to the few compounds revealing a strong within site variation of the carbon isotope ratios. For the three coastal samples determined, $\delta^{13} \mathrm{C}$ values were $-79.8 \%$ o, $-40.4 \%$, and $-40.8 \%$. Given the respective mixing ratios of $1.9,1.0$ and $4.9 \mathrm{pptv}$ no clear relation between variations of the $\delta^{13} \mathrm{C}$ values and of mixing ratios becomes evident. Iodomethane has a relative short atmospheric lifetime of only a few days (Harper and Hamilton, 2003). Therefore both, the mixing ratios and the carbon isotope values, more likely provide a snapshot than an integrated signal, which may explain the lack of any correlation. There are no literature data on carbon isotope ratios of atmospheric iodomethane available to compare with. But our own unpublished data from incubation experiments and greenhouse experiments revealed $\delta^{13} \mathrm{C}$ values of $-47 \pm 11 \%$ o for iodomethane emitted from different halophytes which correspond with the more enriched atmospheric values in our study. The strongly depleted $\delta^{13} \mathrm{C}$ value was determined in air masses coming from the open North Sea while the more enriched $\delta^{13} \mathrm{C}$ values were determined in more coastal influenced air masses. A potential important source in open oceans currently under discussion is the photolytic formation of iodomethane in the sea surface layer (Moore and Zafirou, 1994). Nevertheless, we can currently not substantiate the reasons for the observed large within site variation of the carbon isotope ratios.

\section{- Bromoform:}

A reliable determination of bromoform $\delta^{13} \mathrm{C}$ values was only possible in the coastal samples. In the urban air samples the determination was hampered by co-eluting C8 hydrocarbons. The average $\delta^{13} \mathrm{C}$ values of bromoform in the coastal samples was $-18.3 \pm 4.6 \%$ o $(-22.9 \%$ o, $-13.8 \%$ o and $-18.2 \%$ o). The isotope ratios reported here were corrected for the isotopic shift observed for the standard (see Sect. 4.2.2). Due to this correction we estimated the overall reproducibility for the $\delta^{13} \mathrm{C}$ determination of bromoform to $\pm 4.1 \%$ on the $1 \sigma$ level. This is close to the natural variability in these samples and it thus remains unresolved weather the variability of the $\delta^{13} \mathrm{C}$ values for bromoform reflects the natural variability or simply the analytical uncertainty. As for iodomethane, there are no literature data available on the isotopic composition of atmospheric bromoform. However, similar isotope ratios were reported for bromoform produced in incubation experiments by the brown algae Fucus serratus $\left(\delta^{13} \mathrm{C}\right.$ of $-15 \%$ ) and the planktonic algae Dunaliella tertiolecta $\left(\delta^{13} \mathrm{C}\right.$ of $-24 \%$ ) (Auer et al., 2006). In the same study the $\delta^{13} \mathrm{C}$ value of dissolved bromoform in a sea water sample from the Baltic Sea was determined to $-28 \%$.

\section{- Chloroethane:}

$\delta^{13} \mathrm{C}$ values of chloroethane could only be determined in the samples from the coastal site. In the urban air samples the tailing of the butane peak impeded a reliable carbon isotope ratio determination of this compound. Average mixing ratios were $2.0 \pm 0.7 \mathrm{pptv}$ and the $\delta^{13} \mathrm{C}$ values $(-36.5 \pm 1.7 \%$ ) were comparable to those of chloromethane.

- Vinyl chloride:

Vinyl chloride was only detectable in the urban air samples with mixing ratios of $5.3 \pm 3.5 \mathrm{pptv}$. With an average $\delta^{13} \mathrm{C}$ value of $-0.5 \pm 2.1 \%$ it was strongly 
enriched in ${ }^{13} \mathrm{C}$ as compared to the other chlorinated compounds. To the best of our knowledge, no isotopic data for atmospheric vinylchloride are so far published. Based on our reference standard one might assume a $\delta^{13} \mathrm{C}$ value of $-30.1 \%$ for industrially produced vinyl chloride. In the atmosphere, vinylchloride is rapidly degraded mainly by $\mathrm{OH}$-radicals. The fractionation factor $(\varepsilon)$ of this reaction has not been determined yet. As the OH-radical attacks the double bound it may be in the same order as the $\varepsilon$ of $11.4 \%$ reported for the atmospheric degradation of propene by $\mathrm{OH}$-radicals (Rudolph et al., 2000). In addition, incubation experiments with different soils indicate a large $\varepsilon$ of 21.5 to $26.0 \%$ or the microbial degradation of vinylchloride in soils (Bloom et al., 2000). Thus, this extraordinary high $\delta^{13} \mathrm{C}$ value of vinylchloride may result from its rapid atmospheric degradation and/or evasion of isotopically enriched vinylchloride from sources such as landfills.

\section{- Chloroform:}

Chloroform stable isotope ratios could only be determined in the coastal samples due to strong chromatographic interferences from 2-methyl-1-butene in the urban samples. ${ }^{13} \mathrm{C}$ values analysed were $-33.8 \%$, $-33.1 \%$ and $-44.8 \%$. The relative enriched isotope ratios were observed in air masses from the North and North East respectively while the depleted $13 \mathrm{C}$ value of $-44.8 \%$ was observed in westerly air masses that passed along the Dutch and the German coast. It is noteworthy that this depletion in ${ }^{13} \mathrm{C}$ for chloroform occurred not in the same sample as the depletion in ${ }^{13} \mathrm{C}$ for iodomethane. This depletion in ${ }^{13} \mathrm{C}$ is surprising as it was not accompanied by significant differences in the mixing ratios ( $10.0 \pm 2.1 \mathrm{pptv}, n=3)$. Anyhow the mixing ratios found here for chloroform were by almost two orders of magnitude lower than those reported by Redeker et al. (2007) but the carbon isotope ratios found here fell into the range of $-37.4 \pm 6.4 \%$ given for chloroform in that study. In contrast, the carbon isotope ratios reported for chloroform by Mead et al. (2008) were on average more than $10 \%$ enriched in ${ }^{13} \mathrm{C}$.

\section{- Carbontetrachloride:}

The average found $\delta^{13} \mathrm{C}$ value of carbontetrachloride was $-28.9 \pm 1.9 \% \circ(n=3)$ and average mixing ratios were $104 \pm 8$ for the coastal site. This agrees well with the results of Mead et al. (2008) who reported an average $\delta^{13} \mathrm{C}$ value of $-27.1 \pm 1.2 \%$. The average mixing ratio of carbontetrachloride in the urban samples was $92 \pm 25$ pptv with a mean $\delta^{13} \mathrm{C}$ value of $-36.5 \pm 5.3 \%$. The isotopic signal in the urban air samples might be influenced by incomplete recovery of carbontetrachloride in the target fraction (85 and $90 \%$ ) and thus has to be taken with great care.

\section{- Chlorodifluoromethane:}

In contrast to dichlorodifluoromethane, chlorodifluoromethane was significantly depleted in ${ }^{13} \mathrm{C}$ at the urban site $\left(\delta^{13} \mathrm{C}\right.$ of $-53.2 \pm 4.6 \%$ ) as compared to the coastal site $(-44.2 \pm 3.3 \%)$. Our values from the coastal site resemble those reported in the study of Redeker et al. (2007) who provided an average $\delta^{13} \mathrm{C}$ value of $-42.9 \pm 5.6 \%$ or Belfast (Ireland). More enriched $\delta^{13} \mathrm{C}$ values of $-33.9 \pm 1.0 \%$, have been reported from Bristol, UK (Mead et al. 2009). Interestingly, Redeker et al. (2007) observed a slight although statistically not significant enrichment of ${ }^{13} \mathrm{C}$ for chlorodifluoromethane in northerly air masses as compared to westerly air masses and air masses from Europe.

\section{- Trichlorofluoromethane:}

The isotope ratios of trichlorodifluoromethane were $-29.5 \pm 5.3 \%$ o for the urban site and $-31.5 \pm 2.6 \%$ o for the coastal site. As for dichlorodifluoromethane, no significant differences in $\delta^{13} \mathrm{C}$ between the sites were observed. Our values corroborate the results of Redecker et al. (2007) who gave an average $\delta^{13} \mathrm{C}$ value of $-27.3 \pm 4.4 \%$.

\section{- 1-Chloro-1,1,difluoroethane (HFC-142b):}

The average $\delta^{13} \mathrm{C}$ value for 1-chloro-1,1,difluoroethane was $-24.6 \pm 2.8 \%$ o without any significant difference between both sites.

\section{- Pentafluoroethane, norflurane and bromotrifluoro- methane:}

Unusually ${ }^{13} \mathrm{C}$ enriched carbon isotope ratios were observed for pentafluoroethane $(16.5 \pm 5.3 \%$ ) and norflurane $(4.3 \pm 3.3 \%$ o). A thorough reanalysis of these data revealed interferences on the $m / z 45$ and $\mathrm{m} / \mathrm{z} 46$ signal. As both compounds elute shortly after carbonylsulfide in an interval where the $m / z 46 / 44$ ratio is still affected by sulphur, we presume these interferences to result from the formation of fluorosulfur-compounds in the combustion interface or in the ion source. This is further supported by the carbon isotope ratio measurements of bromotrifluoromethane $\left(\mathrm{CBrF}_{3}\right)$. Interestingly, we observed the opposite effect for bromotrifluoromethane, eluting $15.3 \mathrm{~s}$ after carbonylsulfide. In the urban air samples it was recollected in the same fraction as carbonylsulfide and yielded an average $\delta^{13} \mathrm{C}$ value of $-86.0 \pm 0.4 \%$. Again a reanalysis of our data revealed substantial interferences on the $m / z 45$ and $m / z 46$ signal For the coastal samples, where $\mathrm{CBrF}_{3}$ and carbonylsulfide were recollected in different fractions, we obtained an average $\delta^{13} \mathrm{C}$ value of $-39.1 \pm 10.0 \%$. and found no indication for interferences. $\mathrm{As}_{\mathrm{CBrF}}$ has an average atmospheric lifetime of 65 years and the mixing ratios for both sites were comparable $(3.7 \pm 0.2 \mathrm{pptv})$ this huge discrepancy 
is rather due to the analytical interferences than to atmospheric degradation or source-related processes.

\subsubsection{Variability of the carbon isotope ratios}

Our data reveal considerable isotopic differences between the urban and the coastal sampling site for several compounds. A pronounced enrichment in ${ }^{13} \mathrm{C}$ was observed for 1,1-dichloro-1-fluoroethane $(10.0 \%$ ) and propenal $(7.6 \%)$ in urban samples. The mixing ratios of both compounds were significantly elevated at the coastal site as compared to the urban site (22.6 pptv versus $8.0 \mathrm{pptv}$ and $96 \mathrm{pptv}$ versus $6 \mathrm{pptv}$ ) pointing towards a strong coastal or marine source. In contrast, a pronounced enrichment in ${ }^{13} \mathrm{C}$ was observed for bromomethane $(10.5 \%$ ), chlorodifluoromethane $(9.0 \%)$, and 1,1,1-triflouroethane $(6.7 \%)$ in coastal samples. Concurrently, chloromethane and 1,1,2-trichloro1,2,2-trifluoroethane were less enriched $(3.6 \%$ and $4.0 \%$, respectively).

For chloromethane and bromomethane these differences between both sites are in line with our current understanding of the atmospheric cycling of these compounds. But they are surprising for the long lived CFC's and HCFC's with atmospheric lifetime of several decades along with the lack of any significant actual sources implies a natural variability close to the experimental uncertainty. With exception of the dichlorodifluoromethane measurements at the coastal site, both the within site variability and the in between site variability exceed what one might expect for such inert tropospheric trace gases. If we compare our data with those of Redecker et al. (2007) and Mead et al. (2008), it becomes obvious that the repeatability (reproducibility within a lab) reported in all three studies is comparable. But the average $\delta^{13} \mathrm{C}$ values reported for several (H)CFC's show substantially larger variations pointing towards a poor reproducibility. For instance the average $\delta^{13} \mathrm{C}$ values for dichlorodifluoromethane vary from $-33.5 \%$ to $-41.2 \%$ and those for chlorodifluoromethane vary from $-33.9 \%$ to $-53.2 \%$. If the assumption that these trace gases are inert in the troposphere is valid we can currently state only a poor reproducibility for these compounds.

On other hand we can currently not rule out that CFC's and other long-lived organohalogens are degraded in ocean surface waters (Yvon and Butler, 1996; Yvon-Lewis and Butler, 2002). For carbon tetrachloride the oceanic lifetime driven by hydrolysis has been estimated to 2599 days and might be reduced to 94 days due to (micro)biological activity as suggested by Butler et al. (1997). The estimates of oceanic lifetimes of chlorofluorocarbons that showed an isotopic enrichment in our study range from 1100 days to more than 120000 days without considering an additional biological sink in the oceans. As already pointed out by Yvon-Lewis and Butler (2002), there is substantial evidence for a microbial degradation of chlorofluorocarbons from different environmental settings. If such degradation processes also occur in the surface ocean and are assigned with a substantial large fractionation factor they may imprint the isotopic composition of these trace gases in the atmosphere. Nevertheless, any justification of the isotopic variability of the long lived CFC's and HCFC's require a careful evaluation of potential sources of errors and bias for each compound.

The enrichments in ${ }^{13} \mathrm{C}$ of chloromethane and bromomethane at the coastal site were not accompanied by a significant decrease of the mixing ratios which would point towards an enhanced degradation in the marine boundary layer e.g. due to reactions with chlorine radicals. Therefore, we suppose atmospheric degradation processes not to be the decisive factor for these differences. We assume these isotopic differences are caused by the air sea exchange of these compounds in concert with partial degradation in surface oceans altering the isotopic signatures. Bromomethane from both, intrinsic sources and from the atmosphere, is known to be rapidly degraded in marine surface waters by biotic and abiotic processes with overall degradation rates of up to $20 \%$ per day (King and Saltzman, 1997 and references therein). The abiotic degradation due to hydrolysis and transhalogenation is assigned with a large $\varepsilon$ of $69 \pm 8 \%$ (King and Saltzman, 1997) and the degradation of bromomethane by methylotrophic bacteria is assigned with an $\varepsilon$ of $45 \pm 10 \%$ (Miller et al., 2001). Simultaneously, bromomethane is produced in the surface water. Although the isotopic composition of the intrinsic bromomethane is unknown, it appears reasonable to presume the bromomethane emitted back into the atmosphere to be isotopically enriched considering its rapid degradation and the exceptional strong isotopic fractionation of this process.

\section{Conclusions}

In this study a simple and field suitable cryogenic sampling system for subsequent determination of carbon isotope ratios of a wide range of VOCs was developed. The dry shipper has shown to be a suitable and easy-to-use cooling source that can replace conventional dewars or cryostats in various applications. Up to 30 samples can be taken over a period of two weeks without the need of any technical infrastructure allowing for sampling campaigns in remote areas. Recovery rates for the entire sampling procedure ranged from 92 to $105 \%$ with low standard deviations. The analytical repeatability $(1 \sigma)$ for carbon isotope determination on the 0.2 nmole level ranged from $0.5 \%$ to $2.8 \%$. With a sampling volume of 5001 , carbon isotope ratios of compounds with typical mixing ratios between 1 and 10 pptv can be determined with a precision better than $2 \%$. Nevertheless, the determination of these compounds in urban air masses is often hampered by high loads of hydrocarbons.

We reported isotope ratios for a broad range of VOCs in urban and marine air in Northern Germany. Several compounds have not yet been analyzed for their isotopic 
composition. For the organohalogens having been measured in previous studies the carbon isotope ratios found here are consistent with those previously reported.

The $\delta^{13} \mathrm{C}$ values for bromomethane from the urban site of $-41.5 \pm 3.3 \%$ are in excellent agreement with those reported by Bill et al. (2004). In contrast, bromomethane $\delta^{13} \mathrm{C}$ values were enriched in ${ }^{13} \mathrm{C}$ by about $10 \%$ in the coastal samples. A similar but less pronounced trend was observed chloromethane. We hypothesize that these differences are related to atmosphere-ocean exchange with fractionating biotic and abiotic degradation processes in the surface ocean and suggest carbon isotope ratio determination as a promising tool for better constraining the role of the ocean in the global cycle of these compounds.

\section{Supplementary material related to this article is available online at: http://www.atmos-meas-tech.net/4/2073/2011/ amt-4-2073-2011-supplement.pdf.}

Acknowledgements. The authors of this article would like to thank the BMBF for funding this work within the framework of Sopran (BMBF grant 03F0611E) We also gratefully acknowledge the support of Justus van Beusekom from the AWI Wadden Sea Station in Sylt during the sampling and the support of our the technical staff members Ralf Lendt, Sabine Beckmann and Peggy Bartsch. We are grateful to the reviewers whose comments helped to improve and clarify the manuscript.

Edited by: F. Keppler

\section{References}

Archbold, M. E., Redeker, K. R., Davis, S., Elliot, T., and Kalin, R. M.: A method for carbon stable isotope analysis of methyl halides and chlorofluorocarbons at pptv concentrations, Rapid Commun. Mass Spectrom., 19, 337-342, doi:10.1002/rcm.1791, 2005.

Auer, N. R., Manzke, B. U., and Schulz-Bull, D. E.: Development of a purge and trap continuous flow system for the stable carbon isotope analysis of volatile halogenated organic compounds in water, J. Chromatogr. A, 1131, 24-36, doi:10.1016/j.chroma.2006.07.043, 2006.

Bill, M., Rhew, R. C., Weiss, R. F., and Goldstein, A. H.: Carbon isotope ratios of methyl bromide and methyl chloride emitted from a coastal salt marsh, Geophys. Res. Lett., 29, 1045, doi:10.1029/2001g1012946, 2002.

Bill, M., Conrad, M. E., and Goldstein, A. H.: Stable carbon isotope composition of atmospheric methyl bromide, Geophys. Res. Lett., 31, L04109, doi:10.1029/2003gl018639, 2004.

Bloom, Y., Aravena, R., Hunkeler, D., Edwards, E., and Frape, S. K.: Carbon Isotope Fractionation during Microbial Dechlorination of Trichloroethene, cis-1,2-Dichloroethene, and Vinyl Chloride:? Implications for Assessment of Natural Attenuation, Environ. Sci. Technol., 34, 2768-2772, doi:10.1021/es991179k, 2000 .
Butler, J., Elkins, J., Lobert, J., Montzka, S., and Koropolov, V.: Significant global loss of atmospheric $\mathrm{CCl} 4$ to the ocean, paper presented at AGU Fall meeting, 1997.

Christof, O., Seifert, R., and Michaelis, W.: Volatile halogenated organic compounds in European estuaries, Biogeochemistry, 59, 143-160, doi:10.1023/a:1015592115435, 2002.

Draxler, R. R. and Rolph, G. D.: HYSPLIT (HYbrid SingleParticle Lagrangian Integrated Trajectory) Model access via NOAA ARL READY Website: http://ready.arl.noaa.gov/ HYSPLIT.php, last access: 11 May 2010, NOAA Air Resources Laboratory, Silver Spring, MD, 2011

Giebel, B. M., Swart, P. K., and Riemer, D. D.: $\delta^{13}$ C Stable Isotope Analysis of Atmospheric Oxygenated Volatile Organic Compounds by Gas Chromatography-Isotope Ratio Mass Spectrometry, Anal. Chem., 82, 6797-6806, 2010

Goldstein, A. H. and Shaw, S. L.: Isotopes of volatile organic compounds: an emerging approach for studying atmospheric budgets and chemistry, Chem. Rev., 103, 5025-5048, 2003.

Harper, D. B. and Hamilton, J. T. G.: The Handbook of Environmental Chemistry Vol. 3, Part P, 17-41 DOI 10.1007/b 10456, 2003.

Harper, D. B., Hamilton, J. T. G., Ducrocq, V., Kennedy, J. T., Downey, A., and Kalin, R. M.: The distinctive isotopic signature of plant-derived chloromethane: possible application in constraining the atmospheric chloromethane budget, Chemosphere, 52, 433-436, doi:10.1016/s0045-6535(03)00206-6, 2003.

Keppler, F., Harper, D. B., Röckmann, T., Moore, R. M., and Hamilton, J. T. G.: New insight into the atmospheric chloromethane budget gained using stable carbon isotope ratios, Atmos. Chem. Phys., 5, 2403-2411, doi:10.5194/acp-5-2403-2005, 2005.

King, D. B. and Saltzman, E. S.: Removal of methyl bromide in coastal seawater: Chemical and biological rates, J. Geophys. Res., 103, 18715-18721, 1997.

McCauley, S. E., Goldstein, A. H., and DePaolo, D. J.: An isotopic approach for understanding the $\mathrm{CH} 3 \mathrm{Br}$ budget of the atmosphere, P. Natl. Acad. Sci. USA, 96, 10006-10009, 1999.

Mead, M. I., Khan, M. A. H., Bull, I. D., White, I. R., Nickless, G., and Shallcross, D. E.: Stable carbon isotope analysis of selected halocarbons at parts per trillion concentration in an urban location, Environ. Chem., 5, 340-346, doi:10.1071/en08037, 2008.

Miller, L. G., Kalin, R. M., McCauley, S. E., Hamilton, J. T. G., Harper, D. B., Millet, D. B., Oremland, R. S., and Goldstein, A. H.: Large carbon isotope fractionation associated with oxidation of methyl halides by methylotrophic bacteria, P. Natl. Acad. Sci., 98, 5833-5837, 2001.

Miller, B. R., Weiss, R. F., Salameh, P. K., Tanhua, T., Greally, B. R., Muhle, J., and Simmonds, P. G.: Medusa: A Sample Preconcentration and GC/MS Detector System for in Situ Measurements of Atmospheric Trace Halocarbons, Hydrocarbons, and Sulfur Compounds, Anal. Chem., 80, 1536-1545, doi:10.1021/ac702084k, 2008.

Moore, R. and Zafirou, O.: Photochemical production of methyl iodide in seawater, J. Geophys. Res., 99, 16415-16420, doi:10.1029/94JD00786, 1994

Pupek, M., Assonov, S. S., Muhle, J., Rhee, T. S., Oram, D., Koeppel, C., Slemr, F., and Brenninkmeijer, C. A. M.: Isotope analysis of hydrocarbons: trapping, recovering and archiving hydrocarbons and halocarbons separated from ambient air, Rapid Commun. Mass Spectrom., 19, 455-460, doi:10.1002/rcm.1812, 
2005.

Redeker, K. R., Davis, S., and Kalin, R. M.: Isotope values of atmospheric halocarbons and hydrocarbons from Irish urban, rural, and marine locations, J. Geophys. Res., 112, D16307, doi:10.1029/2006jd007784, 2007.

Rudolph, J. and Czuba, E.: On the use of isotopic composition measurements of volatile organic compounds to determine the "photochemical age" of an air mass, Geophys. Res. Lett., 27, 38653868, 2000.

Rudolph, J., Lowe, D. C., Martin, R. J., and Clarkson, T. S.: A novel method for compound specific determination of $\delta \mathrm{C}^{-13}$ in volatile organic compounds at ppt levels in ambient air, Geophys. Res. Lett., 24, 659-662, 1997.

Rudolph, J., Czuba, E., and Huang, L.: The stable carbon isotope fractionation for reactions of selected hydrocarbons with $\mathrm{OH}-$ radicals and its relevance for atmospheric chemistry, J. Geophys. Res.-Atmos., 105, 29329-29346, 2000.

Thompson, A. E., Anderson, R. S., Rudolph, J., and Huang, L.: Stable Carbon Isotope Signatures of Background Tropospheric Chloromethane and CFC113, Biogeochemistry, 60, 191-211, 2002.
Tsunogai, U., Yoshida, N., and Gamo, T.: Carbon isotopic compositions of $\mathrm{C}_{2}-\mathrm{C}_{5}$ hydrocarbons and methyl chloride in urban, coastal, and maritime atmospheres over the western North Pacific, J. Geophys. Res., 104, 16033-16039, doi:10.1029/1999jd900217, 1999.

Yvon-Lewis, S. A. and Butler, J. H.: Effect of oceanic uptake on atmospheric lifetimes of selected trace gases, J. Geophys. Res., 107, ACH1-1-9, doi:10.1029/2001jd001267, 2002.

Yvon, S. A. and Butler, J. H.: An improved estimate of the oceanic lifetime of atmospheric CH3Br, Geophys. Res. Lett., 23, 53-56, 1996.

Zuiderweg, A., Holzinger, R., and Röckmann, T.: Analytical system for stable carbon isotope measurements of low molecular weight $\left(\mathrm{C}_{2}-\mathrm{C}_{6}\right)$ hydrocarbons, Atmos. Meas. Tech., 4, 11611175, doi:10.5194/amt-4-1161-2011, 2011. 